\title{
Assessment of Socio economic Characteristics of Participant Farmers in Commercial Agriculture Development Project (CADP) in Kaduna State, Nigeria
}

\author{
Manza, E. A. G \\ Department of Agricultural Economics and Extension \\ Kaduna State University \\ Kafanchan Campus, Kafanchan, Kaduna State \\ Nigeria \\ Garba, T.K. \\ Department of Development Finance \\ Central Bank of Nigeria, Jos Branch, Jos \\ Nigeria
}

\begin{abstract}
The aim of the Commercial Agriculture Development Project (CADP) is to help participating small and medium scale farmers to access improved technology, infrastructure, finance and output markets. It strengthens agricultural production systems by supporting the dissemination and adoption of new technologies for targeted value chains amongst them. This study is an empirical evaluation of the impact of socio-economic characteristics of participant farmers of CADP in Kaduna State on yield, output and income. The research findings reveal that participant farmers are more likely to get more yields, with more time spent in CADP and with increase in age. Similarly, more education, time spent in CADP and family size leads to increase in total production while the time spent in CADP has no effect on the number of hectares of land cultivated by participant farmers. The researchers recommend further evaluation of the success or failure of the CADP using different techniques as the lessons learned will go a long way in improving the design and implementation of similar programmes in the future. Also, the researchers recommend that similar programmes like the CADP will help small and medium scale commercial farmers to access improved technology, infrastructure, finance and output marketsas well as strengthen agricultural production systems, supporting the dissemination and adoption of new technologies for targeted value chains among small and medium scale commercial farmers be introduced by government at all levels.
\end{abstract}

Keywords: Commercial Agriculture Development Project, yield, total production and total sales

\section{Introduction}

The importance of agriculture in the development of the socio-economic activities of any country all over the world cannot be overemphasized. This is whyin virtually all developing economies; agriculture is an existing industry of major proportions, frequently the only existing industry of any consequence (Johnston and Mellor, 1961). According to the National Bureau of Statistics(NBS)(2008), Nigeria had a population of over 160 million in 2006, and 182.2 million in 2015 (NPC, 2015) on a land area of 910,802 square kilometers. Nigeria's current population as at May 3rd, 2017 was estimated to be 191,000,565 based on the latest United Nations estimates (Worldometer, 2017). Nigeria ranks number seven in the list of countries and dependencies by population. Nigeria's population is equivalent to $2.55 \%$ of the total world population and $49.9 \%$ of the population is urban dwellers (Worldometer, 2017). In spite of this population, Nigeria faces huge food security challenges i.e. the country is suffering from hunger, poverty and chronic malnutrition. This explains why about 70\% of Nigeria's population lives on less than N100 (US\$ 0.70) per day despite its reputation as petroleum resource dependent, yet it remains an agrarian economy. The agricultural sector provides over $40 \%$ of the Gross Domestic Product (GDP) with between $60 \%$ and $70 \%$ of the population productively engaged in farming. However, large regional differences exist, for instance, in the southeast $22 \%$ of the people live in rural areas with most of them engaged in non-farming activities.

Nigeria has about 80 million hectares of arable land, of which 33 million hectares are cultivated. In spite of this, Nigeria's food import bill rose in 2006 to 2008 despite a 7\% growth rate in agricultural production. Both crop and livestock production remained below potential due to inadequate access to and low uptake of high quality seeds, low fertilizer use and inefficient production systems which have led to this production decadence. 
The sector provides over $40 \%$ of the Gross Domestic Product (GDP) with between $60 \%$ and $70 \%$ of the population productively engaged in farming. However, Nigeria's agriculture is still at a subsistence level due to the negligence suffered by the sector with the discovery, drilling and export of petroleum in commercial quantities in the early 60s.

The former Minister of Agriculture and Rural Development of the Federal Republic of Nigeria, Dr. AkinwunmiAdesina declared in March, 2014 that the National Program for Food Security (NPFS) was still on course and had not been wiped out as reported. He added that NPFS was the primary program on food security and could not be wiped out because of its significance to government's plan of growing the size of the agricultural sector to over 280 billion US Dollars by 2028. The government's major objective was to increase agricultural development programs that focus on increasing food production in order to achieve food self-independency and eradication of food insecurity, while generating through processing and marketing of surplus to improve the standard of living of the over teeming population (ADF, 2008).

The National Program for Food Security was established to answer to the government of Nigeria's decision to address increase in the rate of malnutrition and poverty alleviation in the country. The primary objectives of the Federal Government of Nigeria (FGN)then were to ensure adequate food security and that of poverty reduction. The government's decision in the expansion of the program was based on a recognition of the need to raise the interventions implemented in the pilot phase to the country as a whole, in order to achieve the Millennium Development Goals (MDGs) as enumerated in the National Economic Empowerment and Development Strategy (NEEDS) outlook (FGN, 2008). The NPFS adopted a combined method that covered numerous potential production activities in the agricultural field, including training and capacity building, improvement of rural access roads and markets for farm inputs and outputs, enhancement of crop production and diversification into livestock, fisheries and agro-forestry management among others. These groups of activities were as a result of intervention packages with the participation of the beneficial communities at consultative meetings, which were designed to answer the community needs and production opportunities within the targeted areas by the NPFS.

In an attempt to curb the further the menace of food short fall, the FGN came up with an agency like the National Economic Empowerment and Development Strategy (NEEDS). The policy aims of NEEDS were to be complemented by those contained in the New Agricultural Policy (NAP) and Rural Development Policy (RDP), which emphasized on growth and development of all aspects of agriculture, and increased investment in rural areas. According to $\mathrm{ADF}(2008)$ the country was as a result then faced with the challenges of putting the agricultural growth objectives of NEEDS into feasible and well-coordinated interventions that would increase farm-level productivity, diversify production, strengthen rural market networks, stimulate the emergence of profitable value-adding agro-industries, link producers and processors to domestic, regional and national markets. Nigeria, in spite of her great potentials, has had food shortages and serious protein deficiency for her over teaming population since the eighties. This has caused a continuous rise in the country's import-bill on food items over the years as a result of decreasing domestic production. According tolheanacho and Ogumbameru (1997) Nigeriahad faced serious food and agricultural problems, due to declining per capital food production, increasing food importation and accelerating ecological degradation.

Despite the fact that Nigeria, is endowed with 80 million hectares of arable land and additional 2.5 million hectares of irrigable land, the country has not been able to make judicious use of the climatic conditions, the large expanse of land and ever growing teaming population to make her sufficient in food production in spite of the fact that a variety of crops thrive well with maximum yield in various ecological zones of the country (Oriola, 2009). In an attempt to solve the problem of food production in the country, the FGN had organized various programmes over the years. For example, on May 21st, 1976 the Obasanjo led Military Government launched the Operation Feed the Nation (OFN) (FGN, 2004), the Food and Agricultural Organization (FAO) provided technical and managerial support on demand to the government (FGN, 2006). Despite all of these, the FAO (2004) enlisted Nigeria among countries faced with serious food insecurity problems. Hence, according to Adeyeye (1997) the vision of the country to have physical and economic access to food on a continuous basis still remains a mirage.

In 2009, the Federal Ministry of Agriculture and Water Resources (FMAWR) in collaboration with the World Bank and other stake holders introduced theCommercial Agriculture Development Project (CADP). The aim was to help participating small and medium scale commercial farmers to access improved technology, infrastructure, finance and output markets. It was also aimed to strengthen agricultural production systems and supporting the dissemination and adoption of new technologies, for targeted value chains among small and medium scale commercial farmers in the five participating states. This was timely as the interest in commercial agriculture in Nigeria is growing. The project was implemented in five States of the Federation, namely, Cross-Rivers, Enugu, Kaduna, Kano and Lagos along eight value chains. 
The total number of direct project beneficiaries was estimated at 50,000 (i.e. 10,000 beneficiaries per state) over a period of five years. Small and medium commercial farms were expected to benefit directly while many households would benefit indirectly through access to farm roads, energy and market opportunities.

The CADP project consisted of two components which include agricultural production /commercialization, and Rural Infrastructure. It represented an important attempt to make Nigeria's agricultural growthsustainable, increase employment and reduce poverty in rural areas, and to boostinvestment in new technologies. The project involved significant investments aimed atincreasing domestic food production and improving access to markets through theconstruction and rehabilitation of rural infrastructure. The project supported three value chains in Kaduna State. These value chains are Dairy, Fruit trees and Maize. The value chains chosen by Kaduna State were based on the comparative advantage of the state and their contribution to agricultural growth. Based on an evaluation of market equivalents during appraisal, the value chains selected were expected to have high demand and markets with the capacities to absorb additional productions. To achieve this, a number of interventions were undertaken by the project that include Capacity Building through training of Commodity Interest Groups (CIGs) such as Commercial Agriculture Development Associations (CADAs) in order to develop their capacity to plan and execute the projects;

Market facilitation, which involved market development, awareness and knowledge sharing for commercial farmers through the information kiosks, quality control measures and standards (FMARD, 2015).

Since the introduction of the CADP in Kaduna State, only one empirical study has been conducted to evaluate whether the stated goal was achieved or not. The aim of the study is to evaluate the impact of the CAD project on the beneficiaries from 2009 to 2017 with a view to find whether the participant farmers were impacted positively on their production and as well as income levels. Specifically, the objective of the study is to find answers to the question whether variables such as duration of membership, family size, and educational level affect crop production and income of participants.

\subsection{Materials and Methods}

\subsection{Description of study area}

The area of study is Kaduna State, which comprises of 23 local government councils groupedinto 3 senatorial districts, namely:Northern, Central and Southern senatorial districts. It has a land area of 4.5 million ha with 2.2 million ha under cultivation, and a projected population of 8, 900,951 (NPC, 2016) with 1, 322, 000 farming families (MOAF, 2017). Over $75 \%$ of the citizens of the state are involved in agriculture with about $89 \%$ of them being small scale producers having an average land holding of 1.5 ha (MOAF, 2017).

The average rainfall per annum in the State is between $1300 \mathrm{~mm}$ in the northern part and $1524 \mathrm{~mm}$ in the southernpart.The common crops of comparative advantage being produced include maize, ginger, soya beans, rice, chilies, vegetables, sugar cane and ground nut. The livestock include cattle, small ruminants and poultry. Generally, the agricultural pattern of the state is mixed farming-a process where farmers are involved in the production of both crops and animals.

\subsection{Data collection}

The data used for this study was obtained primarily by administering a questionnaire to 297 randomly selected farmers that participated in the CADP project in 22 LGAs of the State. The design of the questionnaire was such that respondents were required to respond to pertinent questions on the study's aim and objectives, and the variables of interest which include participants characteristics such as bio-data, annual total production before and after joining CADP, total annual sales before and after joining CADP, hectares cultivated before and after joining CADP, and duration of time respondent spent with CADP.

\subsection{Method of data analysis}

Both descriptive and inferential statistical methods have been used in analyzing the data obtained for this study. Specifically, simple descriptive statistics such as bar chart, pie chart and histogram have been used to provide a visual representation of the respondents'socio-economic characteristics. The z-test for paired samples was used to determine whether there exists a significant difference in the farmers' performance before and after joining CADP, the total annual sales before and after joining CADP, and the number of hectares of land cultivated by participant farmers before and after joining CADP. Regression analysis was used to determine whether respondent's age, educational level, family size and duration of time spent with CADP affect annual total production, annual total sales, and number of hectares of land cultivated by the participant farmers. All statistical decisions to accept or reject the null hypothesis have been based on $5 \%$ significance level. 


\subsubsection{Paired samples test}

Paired sample tests have been used to determine whether there exists a significance difference between two sets of observations (Constance et al. (2012). The commonly used paired samples testing are based on parametric approach, specifically t-test for small samples and z-test for large samples. A small sample is a sample of a size less or equal to 30 , and a large sample is a sample of size greater than 30 . The sample size of the data in this study is large, and thus we used z-test. As in many statistical hypothesis testing procedures, paired sample test involve setting two competing hypotheses, the null and alternative hypotheses. The null hypothesis assumes that the true mean difference between the paired samples is zero, while the alternative hypothesis assumes that the true mean difference between the paired samples is not equal to zero.

Let $\bar{X}_{A}$ and $\bar{X}_{B}$ be sample means obtained in large samples $N_{A}$ and $N_{B}$ drawn from normally distributed populations with means $\mu_{A}$ and $\mu_{B}$, and standard deviations $\sigma_{A}$ and $\sigma_{B}$, respectively. For the problem of testing a null hypothesis $H_{0}: \mu_{A}-\mu_{B}=0$ against an alternative $H_{1}: \mu_{A}-\mu_{B} \neq 0$. A z-statistic is calculated by $z=\left(\bar{X}_{A}-\bar{X}_{B}\right) / \sqrt{\frac{\sigma_{A}^{2}}{N_{A}}+\frac{\sigma_{B}^{2}}{N_{B}}}$,

Which under $H_{0}$ is normally distributed with mean zero and variance equal to 1 . Thus, if the calculated z-value is greater than the $\mathrm{z}$-value in the standard normal distribution for a given $\alpha$-value, the null hypothesis is rejected, otherwise it is accepted. However, the analysis presented in this paper is based on the use of p-value, and the null hypothesis is rejected if the p-value is less than the pre-specified significance level.

\subsubsection{Linear regression}

Regression analysis is an important statistical method for the analysis of data that enables the identification and characterization of relationships among multiple factors. It allows the identification of prognostic relevant risk factors and the calculation of risk scores for individual prognostication. For example, one would like to know not just what leads to high annual total production, annual total sales, and cultivation of large hectares of land by participant CADP farmers, but also whether the likelihood of the above mentioned variables was influenced by socio-economic factors such as age, educational level, family size and duration of time spent with CADP by participant farmers (Selvin, 2001). The variable to be explained (annual total production, annual total sale or hectares of land cultivated) is called the dependent variable, or, alternatively, the response variable; the variables that explain it (age, educational level and duration of time spent with CADP) are called independent variables or predictor variables. (Bortz, 2004). Regression analysis employs a model that describes the relationships between the dependent variables and the independent variables in a simplified mathematical form.

\subsection{Results and discussion}

\subsection{Description of socio-economic characteristics of CADP farmers}

The bar chart below shows the distribution of the number of participants in the CADP according to their Local Government Areas. It can be observed that the highest number of participants is from Giwa Local Government Area, followed by Lere and Kubau. This should be expected as indigenes of these Local Government Areas accepted the CADP whole heartedly since they showed a willingness to provide the counterpart funds required for project implementation.

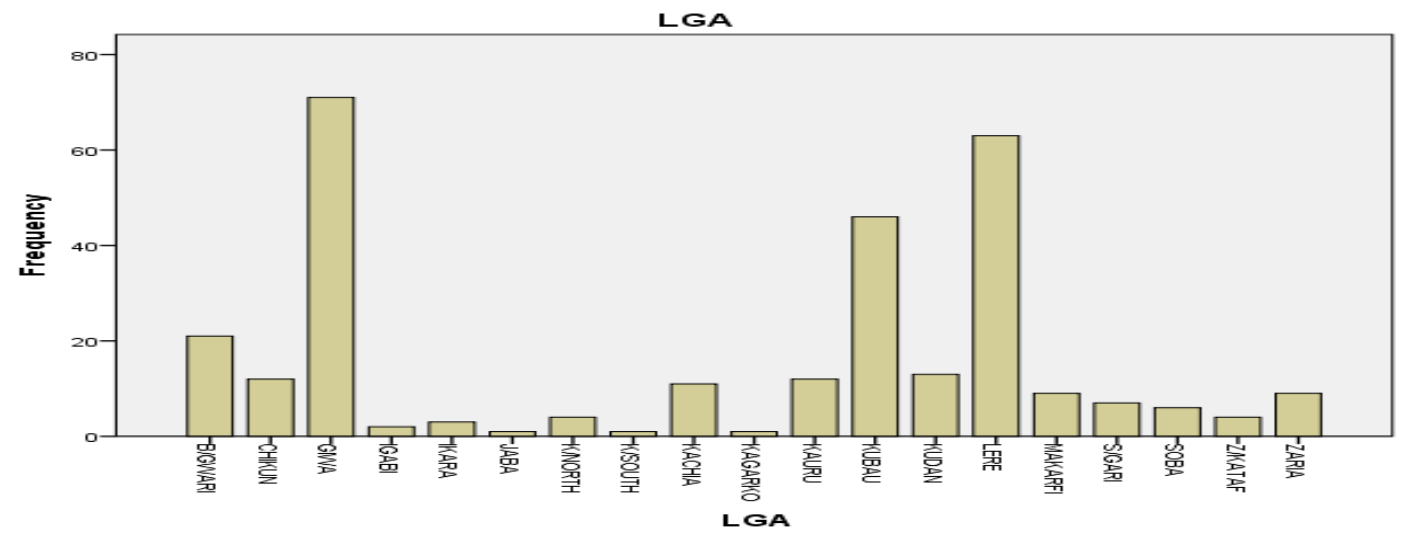

Figure 1: Bar chart showing the distribution of CADP participants according to Local Government Area of origin. 
Figure 2 shows that most of the participants of CADP are males constituting about $89.5 \%$, while the female are only $10.5 \%$ of the total participants. This should equally be expected as farmingis generally considered as occupation mainly for the males. A finding like this may be attributed to the tradition and custom of the people where only the male own land. Furthermore,women are into other non-farm activities and also domestic activities such as taking care of the family and cleaning the house (Musa,2011).

Musa(2011) in a study of the marginalised and vulnerable participants of the Fadama II project in Kaduna State,Nigeria found that the male participants were $61.7 \%$ as against $71.8 \%$ of the male non-participants. The participating women were $38.3 \%$ as against the non-participating women who were $28.2 \%$.

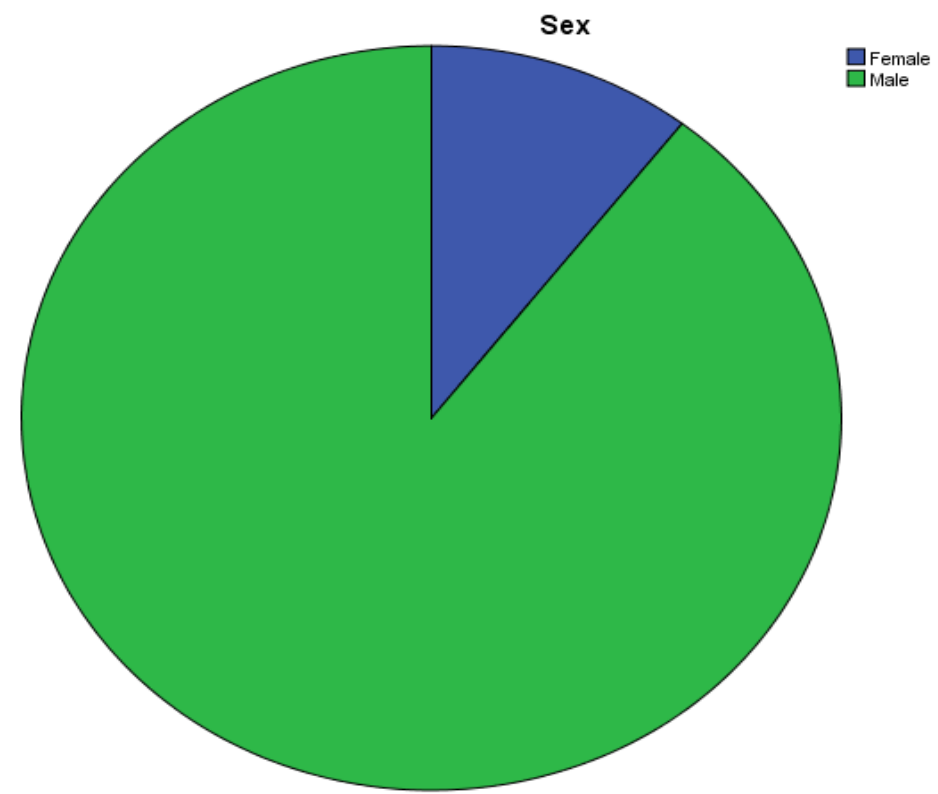

Figure 2: Pie chart showing the distribution of CADP participants according to Sex

Table 1 shows the distribution CADP participants according to highest educational level attended. Most of the participants finished secondary school (49\%), followed by holdersof Nigeria Certificate in Education (NCE)/Ordinary National Diploma (OND) certificate holders (13.9\%) then Primary school leavers $(10.8 \%)$. The least number of participants completed postgraduate training (5.1\%).

Adebayo (2011), in a study of United Nations Development Programme beneficiaries and non-beneficiaries in Kaduna State showed $37.5 \%$ and $48.8 \%$ of the beneficiaries and non-beneficiaries had no formal education. $30.4 \%$ and $16.1 \%$ of the beneficiaries had primary and secondary education among the beneficiaries respectively. Among the nonbeneficiaries, $24.1 \%$ and $9.1 \%$ had primary and secondary education respectively. On the other hand $16.1 \%$ and $18.1 \%$ of the beneficiaries and non-beneficiaries had post-secondary education. It is important to note that the need for education in agricultural production cannot be over emphasized.

Imonike(2004) in Simonyan(2009) state that education would significantly enhance farmers'ability to make accurate and meaningful management decisions which could also enhance knowledge of improved techniques such as how to read and interpret recommended packages.Adebayo (2011) argues that education inagricultural production will assist farmers to accept and test innovations that are available, and enhance the ability to make informed and accurate management decisions.

Table 1: Educational level of participating farmers

\begin{tabular}{cll}
\hline Educational Level & Frequency & Valid Percent \\
\hline No education & 22 & 7.5 \\
Informal & 23 & 7.8 \\
Primary & 32 & 10.8 \\
Secondary & 145 & 49.2 \\
NCE/OND & 41 & 13.9 \\
Graduate & 17 & 5.8 \\
P/Graduate & 15 & 5.1 \\
Total & 295 & 100.0 \\
\hline
\end{tabular}

Field Survey Data, 2017 
The bar chart below shows that the majority of the participants have family size of 4-6 followed by 25-27 and 10-12. There are households with family size of 40-42 and 43-45.This result is comparable with the findings of Musa (2011) where majority of the participants and non-participants (70\% and 65\% respectively) had family sizes of $6-15,1-5 ; 14 \%$ and $15 \%$ for the two sampled groups, $16-20$ had $7 \%$ and $8 \%$, while those with the least family size of 30 and above had $2 \%$ and 3\% respectively. According to Akinyemi (1998) in Musa (2011) a household (family) size is an important factor in traditional agriculture because it influences to a large extent the supply of labor for immediate farm operations.

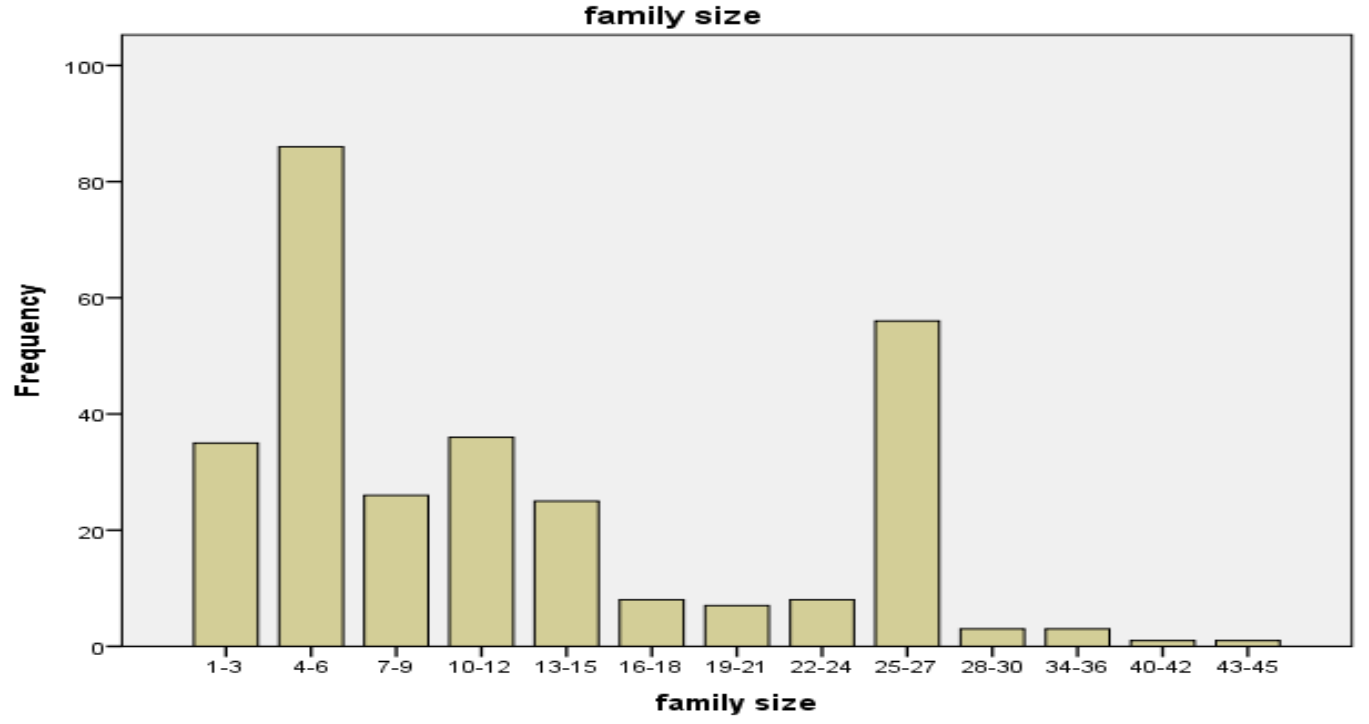

Figure 3: Bar chart showing the distribution of CADP participants according to Family Size

The age of a farmer determines the quality and quantity of work he or she can do on his/her farm. It is an important measure of farm productivity. (Adebayo,2011). Figure 4 shows that majority of the particpants in the CADP are between the age 40-49 years followed by ages 50-59 years and ages 30-39 years. The lowest age bracket is ages 70-79 years followed by ages 20-29 years. According to Jibowo (1996) in Adebayo (2011) the age group 40-49 is a very productive age group.

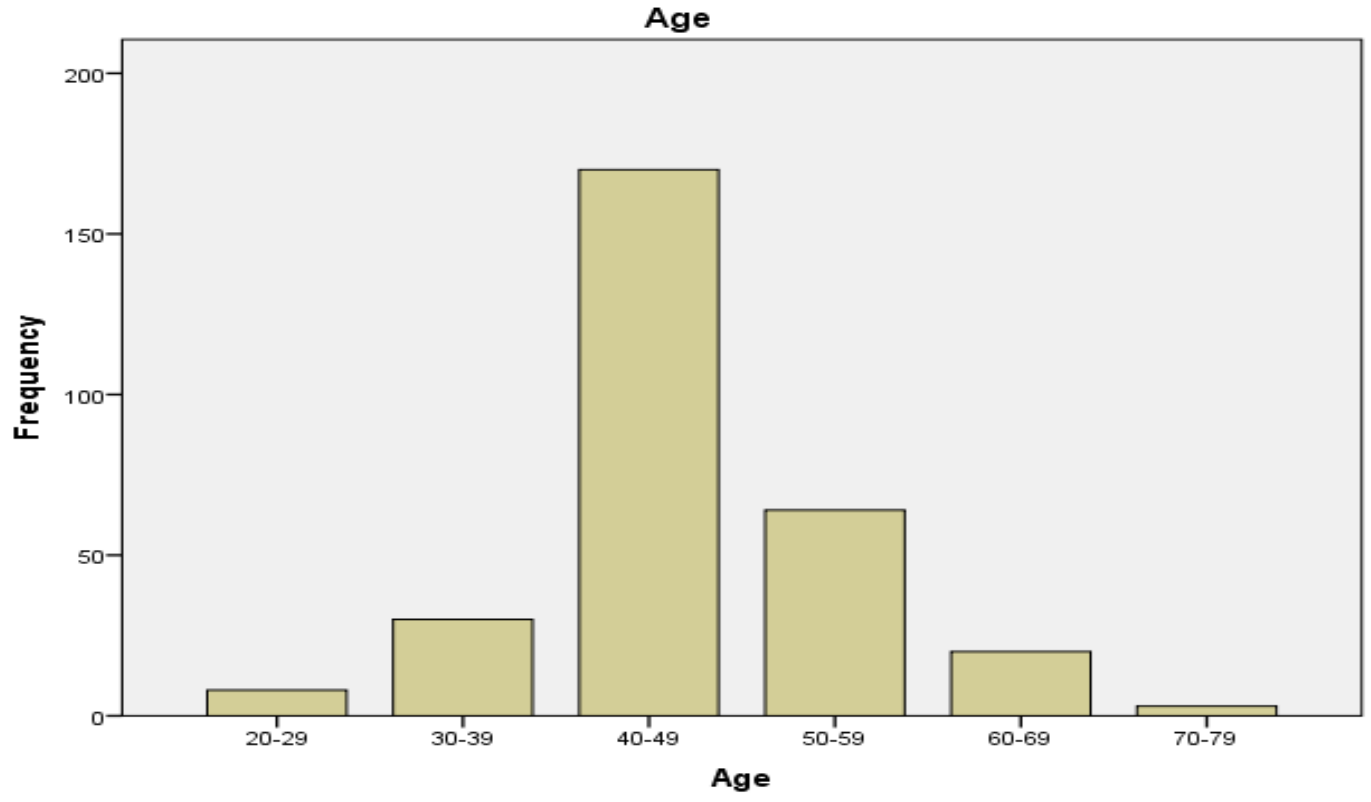

Figure 4: Bar chart showing the distribution of CADP participants according to Age 
The pie chart below shows that most of the participants in the CAD project are farmers followed by civil servants, marketing and business. This finding agrees with that of Manza and Atala (2014) in which they found that $84.4 \%$ and $58.9 \%$ of the beneficiaries (PROSAB farmers) and non-beneficiaries (non-PROSAB farmers) respectively were into farming as a primary occupation. This was followed by $12.8 \%$ and $26.7 \%$ who were into civil service employment for the beneficiaries and non-beneficiaries respectively. Based on their finding, they concluded that their finding had an important implication for farm production decisions by the households. That is, the dependence of farm families of farming as the predominant occupation may have a positive or negative effect on agricultural production depending on the availability and allocation of household resources.

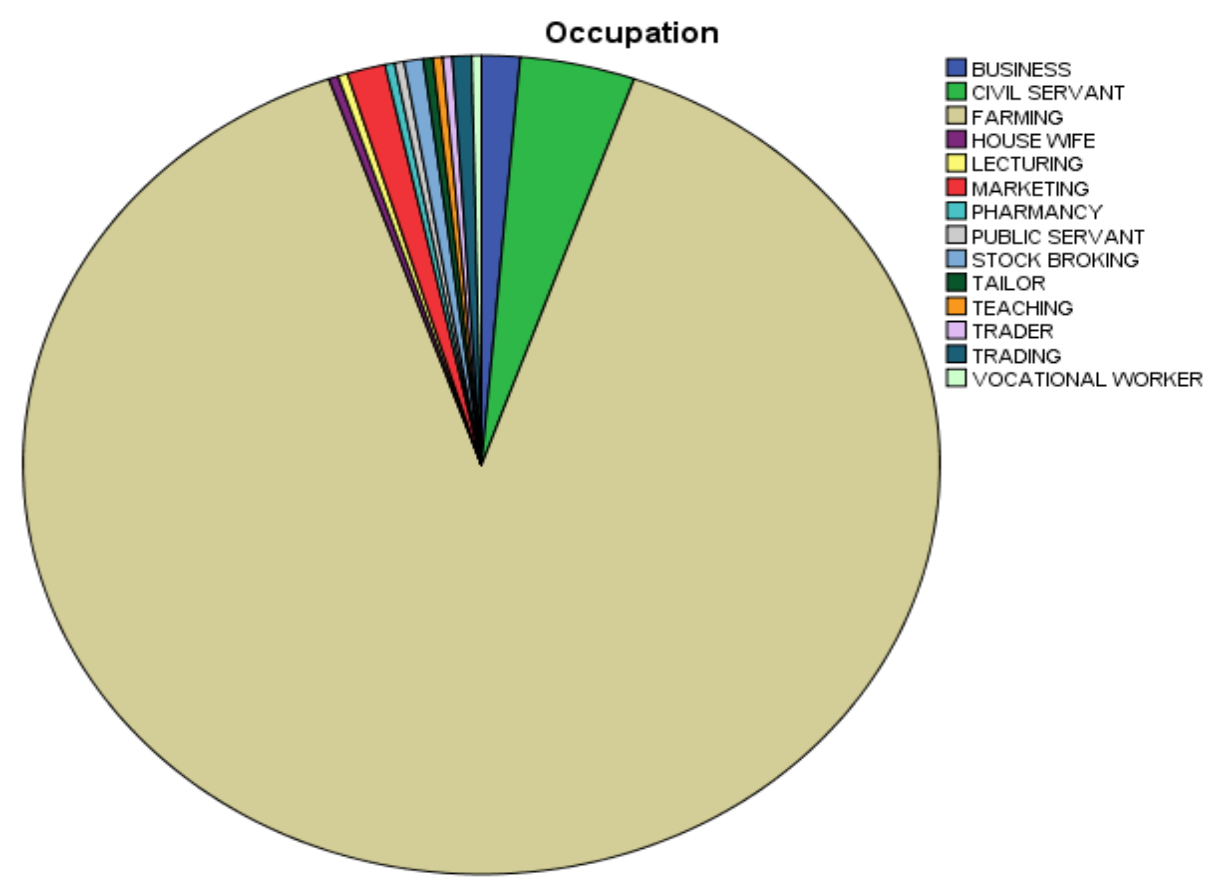

Figure 5: Pie chart showing the distribution of CADP participants according to Occupation

\subsection{Impact of CADP on Participant Farmers'}

The impact of CADP on the participant farmers was evaluated using z-test to determine whether there exists a significant difference between crop yield before and after joining CADP. The result shows that the average yield before and after of $39.87 \mathrm{~kg} / \mathrm{ha}$ and $59.43 \mathrm{~kg} / \mathrm{ha}$ respectively is significant at $5 \%$ significance level with a z-value of 7.33 and pvalue of 0.00. Similarly, a statistical significant result was observed between the number of hectares of land cultivated before and after CADP with a z-value of 2.04 and p-value of 0.04 . The average total production before and after CADP is found to be $4,895.47 \mathrm{~kg}$ and $6,164.88 \mathrm{~kg}$, respectively, which indicates a significantly result with a z-value of 4.34 and p-value of $1.44 \mathrm{e}-05$.

On the assessment of the impact of CADP based on income, a significant improvement in participant farmers' output index was observed from an average of 36.77 to 226.42 with a $\mathrm{z}$-value of 2.08 and p-value of 0.037 . The average total sales index equally increased significantly from an average of 2.90 to 6.78 with a z-value of 5.95 and a p-value of 2.71e-9, this should be expected since there is an increased in total production.

\subsection{Effect of Socio-economic Characteristics on Participant Farmers Performance}

The socio-economic characteristics considered in this analysis include age, educational level attained, family size and duration of time spent with CADP, and the performance indices considered arethe number of hectares of land cultivated, annual total production, total output, and total sales. Table 2 shows the regression analysis of yield against the socioeconomic characteristics. Although no significant result is observed, however, the positive values in the estimates of duration and age indicate that a farmer is likely to get more yields with more time spent with CADP and with increase in age. This result agrees with Farinde and Adesoji (2006)who reported thata farmer's age as a variable had no significant role to arable crop production in Osun State, but it had positive impact to a certain extent. If the age of an arable crop farmer should increase by 1 year, the production will increase by 2.57 tons per year. The increase in age to increased production could continue to about 52 years (mean age). This might be due to the experiences acquired due to the age over time. 
However, the duration (represented as the number of trainings and demonstrations attended) was significant at $1 \%$. If the number of demonstrations and training attended by arable crop farmers could increase by one unit, yield of arable crops would increase by 7.10 tons per annum.

Table 2: Regression Analysis of Yield against the Socio-economic Characteristics of CADP Participants

\begin{tabular}{lclll}
\hline Co-efficientsEstimate & Std. Error & $\mathrm{t}$-value & $\operatorname{Pr}(>|\mathrm{t}|)$ & \\
\hline Intercept & 63.63784 & 19.64781 & 3.239 & $0.00139 * *$ \\
Educational.leve.1 & -10.52055 & 11.31188 & -0.930 & 0.35340 \\
Educational.level.2 & -6.99069 & 10.21393 & -0.684 & 0.49445 \\
Educational.level.3 & -9.71556 & 8.83037 & -1.100 & 0.27246 \\
Educational.level.4 & -18.48312 & 9.93892 & -1.860 & 0.06430 \\
Educational.level.5 & -8.03935 & 12.98604 & -0.619 & 0.53652 \\
Educational.level.6 & -10.81152 & 13.07128 & -0.827 & 0.40909 \\
Duration 0.50276 & 1.86026 & 0.270 & 0.78722 & \\
Age 0.07651 & 0.31401 & 0.244 & 0.80774 & \\
Familysize-0.06263 & 0.34792 & -0.180 & 0.85732 & \\
\hline
\end{tabular}

Field Survey Data, 2017

Signif.codes: 0 '***’ 0.001 '**' 0.01 '*' $0.05^{\prime}$ '? 0.1 ' ' 1

In Table 3, the regression analysis indicates that only duration in the CADP was significant.However, its regression coefficient indicates a negative sign. This means that the time spent with CADP does not lead to increase in the number of hectares of land cultivated by participant farmers. Oluwasola (2012) reported that family size and farm income were positively correlated with farm size and the two variables were statistically significant at $5 \%$. That is to say a unit increase in family size will increase farm size by $13.2 \%$. This is quite understandable since an increase in family size will provide extra labour to work on the farm. It also shows that the family unit in the study area was productive and that all members of the household were engaged in the farm business. Age on the other hand was negatively correlated with farm size; it was however not statistically significant.

Table 3: Regression Analysis of Numbers of Hectares Cultivated against the Socio-economic Characteristics of CADP Participants

\begin{tabular}{lcccc}
\hline Coefficients & Estimate & Std. Error & $\mathrm{t}$-value & $\operatorname{Pr}(>|\mathrm{t}|)$ \\
\hline Intercept 10.04208 & 8.07824 & 1.243 & 0.2149 & \\
Educational.level.1 & -1.23868 & 4.92972 & -0.251 & 0.8018 \\
Educational.level.2 & 1.37211 & 4.47813 & 0.306 & 0.7595 \\
Educational.level.3 & -0.15650 & 3.80586 & -0.041 & 0.9672 \\
Educational.level.4 & 2.64413 & 4.27803 & 0.618 & 0.5370 \\
Educational.level.5 & -2.22897 & 5.18680 & -0.430 & 0.6677 \\
Educational.level.6 & 0.35378 & 5.47010 & 0.065 & 0.9485 \\
Duration -1.49153 & 0.74384 & -2.005 & $0.0459 *$ & \\
Age 0.07281 & 0.12999 & 0.560 & 0.5759 & \\
Family.size 0.06912 & 0.12268 & 0.563 & 0.5736 & \\
\hline
\end{tabular}

Field Survey Data, 2017

Significant codes: 0 ‘***’ 0.001 '**’ 0.01 '*’ 0.05 '? 0.1 ' ’ 1

In Table 4, a significant result is observed in educational level 5 (graduate), meaning that participant graduate farmers in CADP are likely to produce more. This should be expected even the CADP program was meant to provide technical services, and thus participant graduate farmers are more likely to gain due to their level of education. The positive values in the estimates of educational level, duration and family size indicate that increase in these values will lead to increase in total production.

Julius and Job (2012) found that household size was significant $(\mathrm{p}<.05)$ and positively related to output. Their data suggested that an average maize farmer increased maize output for family consumption by approximately $29 \mathrm{~kg}$ for every extra person in the household. The positive relationship was in line with the a priori expectation because it implied that an increase in household size leads to an increase in maize production. 
Table 4: Regression Analysis of Total Production against the Socio-economic Characteristics of CADP Participants

\begin{tabular}{lccll}
\hline Co-efficients & Estimate & Std. Error & $\mathrm{t}$-value & $\operatorname{Pr}(>|\mathrm{t}|)$ \\
\hline Intercept & 62.97383 & 15.91229 & 3.958 & 0.000101 *** \\
Educational.level.1 & 12.67345 & 9.49832 & 1.334 & 0.183430 \\
Educational.level.2 & 4.91833 & 8.70091 & 0.565 & 0.572443 \\
Educational.level.3 & 11.09820 & 7.57552 & 1.465 & 0.144284 \\
Educational.level.4 & 15.04111 & 8.44935 & 1.780 & 0.076372. \\
Educational.level.5 & 27.73986 & 10.04475 & 2.762 & $0.006216 * *$ \\
Educational.level.6 & 5.96656 & 11.05356 & 0.540 & 0.589867 \\
Duration & 1.08994 & 1.44575 & -0.754 & 0.451686 \\
Age & -0.42856 & 0.25751 & -1.664 & 0.097429 \\
Family size & 0.09762 & 0.29086 & 0.336 & 0.737466 \\
\hline
\end{tabular}

Field Survey Data,2017

Signif.codes: 0 ‘***’ 0.001 '**’ 0.01 '*’ 0.05 '? 0.1 ‘ ’ 1

Table 5 shows the regression analysis of total output against the socio-economic characteristics. Although no significant resultwas observed, however, the positive signs in the regression coefficients of educational levels $1,3,4,5$ and 6, duration and family size means that an increase in these values will result in increase in the total Farm products. Igbojiet. al. (2015) found that the coefficient of age was positively signed but not statistically significant. This implies that positive relationship exists between the age of a farmer and the total output of rice production in the area. The situation indicates that older farmers are more skillful in the rice production; hence the a priori expectation was met.The coefficient of household size bore a positive coefficient indicating that household size has a positive influence on the output of rice farmers in the study area. The implication was that members of a household contribute significantly to family labour supply which leads to increase in rice total output. This reduces the cost of production since family labour is not paid for.

The educational qualification of rice farmers bore a positive signed coefficient and was not statistically significant. The positive relationship indicated that the higher the level of education of the farmers, the higher their total output in rice production. This is true because educated farmers are intelligent and calculative in the utilization of available resources and are able to adopt innovation on rice products. Unlike uneducated farmers who have low adoption level. Furthermore, it also implied that better education improved awareness of potential benefits increases willingness to participate in local naturalresource management and conservation activities. The farming experience (which could be considered as duration of rice farming) of the respondents also showed positive coefficient but statistically insignificant. This meant that an increase in the years of farming experience led to a corresponding increase in the output of the farmers. This is true because farmers who have higher farming experience are likely to be more knowledgeable in the combination of resources. This was in line with the apriori expectation because rice farmers with high level of farming experience obtained increased total output due to higher efficiency in resource use. They were technically, economically and allocatively more efficient than others who have low level of farming experience.

Table 5: Regression Analysis of Total Output against the Socio-economic Characteristics of CADP Participants

\begin{tabular}{lccll} 
Co-efficients & Estimate & Std. Error & \multicolumn{2}{c}{$\mathrm{t}$-value $\operatorname{Pr}(>|\mathrm{t}|)$} \\
\hline Intercept & 35.05688 & 13.15467 & 2.665 & $0.00816^{* *}$ \\
Educational.level.1 & 6.28368 & 7.94239 & 0.791 & 0.42954 \\
Educational.level.2 & -5.79344 & 7.25067 & -0.799 & 0.42497 \\
Educational.level.3 & 3.13846 & 6.18017 & 0.508 & 0.61199 \\
Educational.level.4 & 6.45651 & 7.00949 & 0.921 & 0.35781 \\
Educational.level.5 & 16.37550 & 8.39486 & 1.951 & 0.05212 \\
Educational.level.6 & 8.87386 & 8.85023 & 1.003 & 0.31691 \\
Duration & 0.48726 & 1.20532 & 0.404 & 0.68634 \\
Age & -0.09711 & 0.21701 & -0.447 & 0.65487 \\
Family size & 0.03258 & 0.19954 & -0.163 & 0.87043 \\
\hline
\end{tabular}

Field Survey Data,2017.

Signif.codes: 0 ‘***’ 0.001 '**' 0.01 '*’ 0.05 '. 0.1 ‘ ’ 1 
In Table 6, no significant result was observed in the regression analysis of the total sales against the socioeconomic characteristics. However, the positive signs in the estimates of educational levels 1, 3, 4 and 5, and also in duration and family size mean that an increase in these values will result in increase in total sales. This result should be appreciated as it indicates that the CADP intervention, impacted positively on the participant farmers.

Mumbaet. al. (2012) summarizes the multiple regression estimates of factors affecting profitability (total sales - total cost of production) of smallholder dairy enterprise. Age of the farmer had a positive coefficient but not statistically significant. This meant that this variable had no effect on the profitability of smallholder dairy farming, provided other variables were held constant. All the farmers regardless of age had equal chances of making profit. However, a unit increase in age would lead to an increase in the profit of smallholder dairy enterprise by US\$ 6.5. The coefficient of household size was positive though not statistically significant. This meant that a unit increase in the number of persons at home would increase the profit of smallholder dairy enterprise by US\$ 6 . Household size has been described as the most important determinant of labour investment for family farms because in addition to being a source of labour, it also influences the need for increased milk production for home consumption as well as for the market (Ngongoniet al., 2006 in Mumbaet. al., 2012).

Mumbaet. al. (2012) also reveals that the level of education was statistically significant (0.01) and had a positive value. This meant that the higher the level of education, the more the profit. This had to do with the understanding of smallholder dairy farming as a business. This understanding resulted in proper management of dairy animals, feeding and good milk hygiene, thereby improving milk yield and profits. A unit increase in level of education led to an increase in profit by US\$ 413.

Table 6: Regression Analysis of Total Sales against the Socio-economic Characteristics of CADP Participants

\begin{tabular}{lcccc} 
Co-efficients & Estimate & Std. Error & t-value & $\operatorname{Pr}(>|t|)$ \\
\hline Intercept & 5.39300 & 6.55911 & 0.822 & 0.4135 \\
Educational.level.1 & 6.17625 & 3.86782 & 1.597 & 0.1144 \\
Educational.level.2 & -1.25476 & 2.89129 & -0.434 & 0.6655 \\
Educational.level.3 & 0.36751 & 2.60968 & 0.141 & 0.8884 \\
Educational.level.4 & 2.88326 & 2.92588 & 0.985 & 0.3275 \\
Educational.level.5 & 5.68754 & 3.38317 & 1.681 & 0.0968 \\
Educational.level.6 & -4.06801 & 4.14933 & -0.980 & 0.3300 \\
Duration & 0.05980 & 0.60907 & 0.098 & 0.9220 \\
Age & -0.02858 & 0.08845 & -0.323 & 0.7475 \\
Family size & 0.12460 & 0.07076 & 1.761 & 0.0822 \\
\hline
\end{tabular}

Field Survey Data, 2017.

Signif.codes: 0 ‘***' 0.001 '**’ 0.01 '*' 0.05 '? 0.1 ' ' 1

\section{Conclusion}

This article was aimed at serving as an empirical study on the activities of CADP in Kaduna State with the main objective to evaluate whether the socio-economic characteristics of participant farmers impacted positively to the success of the programme. Although no significant result is observed, the findings show that participant farmersare more likely to get more yields with more time spent in CADP and with increase in age. Similarly, more education, time spent in CADP and family size leads to increase in total production. In contrast, the time spent in CADP does affect the number of hectares of land the participants farmers cultivate positively.

\section{Recommendations}

The researchers recommend further assessment and evaluation of the success or failure of the CADP using different techniques by various professionals as the use of lessons learned will go a long way in improving the design and implementation of similarprogrammes in the future. Finally, the researchers recommend that more programmes like the CADP will help small and medium scale commercial farmers to access improved technology, infrastructure, finance and output markets as well as strengthen agricultural production systems, supporting the dissemination and adoption of new technologies for targeted value chains among small and medium scale commercial farmersbe introduced by government at all levels.

\section{References}

Adebayo, O.O. (2011). The Impact of the United Nations Development Programmes' (UNDP).Micro-Credit Scheme on Food Security Status of Farm Households, Kaduna State.Ph.DAgricultural Economics Thesis, Ahmadu Bello University, Zaria, Nigeria. 
Bortz, J.(2004). Statistikfür Human-und Sozialwissenschaftler.6th edition. Heidelberg: Springer.

Constance, A. M.\& Robert, A. C.(2012).Paired-Samples Tests of Equivalence,Communications in Statistics Simulation and Computation, 41:10, 1928-1943.

Farinde, A. J. and Adesoji, S. A. (2006). Socio-Economic Factors Influencing Yield ofArable Crop in Osun State, Nigeria. Asian Journal of Plant Sciences, 5: 630-634.

Igboji, C., Anozie, R.O. and Nneji C. P.(2015). Analysis of Socio - EconomicFactors andProfitability of Rice Production among Small-scale Farmers in Ebonyi State. Journal of Agriculture and Veterinary Science.8(2):20 $-27$.

Federal Ministry of Agriculture and Rural Development(FMARD)(2015). Commercial Agriculture Project(CADP). Revised Project Implementation Manual Prepared by the National Coordinating Office of the Commercial Agricultural Development Project, Abuja, Nigeria. Final Copy (October 09,2015) Pp.138.

Imonike, G.A. (2004).Impact of Katsina State Agriculture and Community Development Project on Income and Productivity of Farmers. Ph.D Thesis in the Department of AgriculturalEconomics and Rural Sociology, Ahmadu Bello University, Zaria, Nigeria.

Johnston, B. F. \& Mellor, J. W. (1961).The role of agriculture in economic development.The American Economic Review, 51(4), 566-593.

Julius, A. and Job, N. N. (2012).Socio-economic Factors Influencing the Output ofSmall-Scale Maize Farmers in Abuja, Nigeria.Kasetsart Journal of Social Sciences. 33 : $333-341$

Manza, E.A.G. and Atala, T.K. (2014). Socio-Economic Characteristics of Farming Households in the PROSAB and Non-PROSAB Areas of Southern Borno State, Nigeria.Taraba Journal of Agricultural Research(TAJAR).Vol.2 No.2. Pp.44-53.

Mumba, C., Samui, K. L., Pandey, G. S. and Tembo, G. (2012). Econometric analysis of the socio-economic factors affecting the profitability of smallholder dairy farming in Zambia.Livestock Research for Rural Development 24 (4). Retrieved $23^{\text {rd }}$ January, 2018 from http://www.lrrd.org/lrrd24/4/mumb24066.htm

Musa, R.S. (2009).Impact of Fadama II Development Project on the Income of Benefitted Marginalised and Vulnerable Groups in Kaduna State.Ph.D Agricultural Economics Thesis,Department of Agricultural Economics and Rural Sociology,Ahmadu Bello University, Zaria,Nigeria.

Oluwasola, O. (2012). Integrating Small Holder Food Crop Farmers into the National Policy for Commercialization and Large Scale Agriculture in Nigeria: a Case Study of Ekiti State.International Journal of Agriculture and Forestry.2(5): 247-256

Selvin, S.(2001).Epidemiologic Analysis.Oxford University Press.

Simonyan,J.B.(2009). An Impact Assessment of Fadama II Project on Income andProductivity of Beneficiary Farmers in Kaduna State Ph.D Agricultural Economics Thesis,Department of Agricultural Economics and Rural Sociology, Ahmadu Bello University,Zaria, Nigeria. 